\section{Statistics Software}

A variety of good packages were mentioned, including Minitab, SPSS/PC+, NCSS, MYSTAT, and Systat. Choosing the best package depends on individual needs (see Butler \& Neudecker, 1989).

\section{Obtaining Software}

It is possible to obtain some expensive programs at very low cost. To do so, one must negotiate and make a multiple purchase from an educational institution. It was reported that Word Perfect (with manuals) had been obtained for as little as $\$ 65$.

\section{User Group}

The group planned to share addresses and to do some future communication using the COMPSYSCH bulletin board.

\title{
Macintosh and Apple II
}

\author{
JONATHAN VAUGHAN, Facilitator \\ Hamilton College, Clinton, New York
}

Some 25 Apple users met to exchange technical information and insights concerning the use of Apple computers in psychology. The discussion addressed such topics as real-time laboratory control, graphics, the use of intelligent peripheral devices for laboratory control, and software useful in the classroom, with emphasis on the Macintosh line of computers. Enthusiasm was expressed both for the power and versatility of leading-edge technology, and for the economy and reliability of trailing-edge technology. The group decided to establish a mailing list of attendees, so that an informal network of Apple users might be nurtured.

\section{Digital Equipment Corporation's PDP-11 computers}

\author{
STEPHEN E. EDGELL, Facilitator \\ University of Louisville, Louisville, Kentucky
}

Although attendance was small, there was a good discussion of the use of PDP-11 computers to run psychology laboratories. Also discussed was the superior power of such operating systems as RSX, as compared with those usually available for the PDP-11, to control several smart hardware boxes, which in turn control research stations. 